\title{
Predicting the Behaviour of Reinforced Concrete Slabs at Elevated Temperature Using Finite Shell Element Analysis
}

\author{
Y. C. Wang \\ Building Research Establishment \\ Garston Watford WD2 7JR \\ UK
}

\begin{abstract}
As part of a numerical study into the structural behaviour of complete buildings under fire conditions, a computer program has been developed to predict the response of shell structures. This paper describes the basic formulations used in the analysis and presents some benchmark results to illustrate the capacity and accuracy of the program as applied to floors and walls at elevated temperature.
\end{abstract}

KEYWORDS Finite element method, Shell, Elevated temperature, Reinforced concrete slabs

\section{INTRODUCTION}

It appears that numerical studies on the behaviour of load bearing structures under fire conditions have mainly concentrated on predicting the behaviour of individual beams and columns and frames composed of such members. The structural performance of other load bearing components of a building i.e. floors and walls under fire conditions has not received much attention. Using the finite element method where beam elements and non-conforming triangular plate bending elements are used to represent the frame and slab of a building, a computer program known as FASBUS II has been developed to predict the fire endurance of flooring systems composed of steel beams and a concrete slab[1]. Nizamuddin and Bresler [2] also used triangular elements to study the fire response of reinforced concrete slabs. Using the moment-curvature method, O'Meagher and Bennetts [3] studied the behaviour of concrete walls in fires, essentially treating a wall as a column under uniaxial loading.

Applying the finite element method, the author has developed a computer program to simulate the behaviour of a skeletal frame under fire conditions using beam elements [4]. As part of a project to study the structural behaviour of complete buildings under fire conditions using numerical methods, shell elements representing floors and walls are introduced into the program. This paper describes the basic formulations of the finite element analysis of shell structures under fire conditions and presents some numerical results on reinforced concrete plates to illustrate the capacity and accuracy of the program. 


\section{GENERAL PRINCIPLES}

The response of a structure to loads is a nonlinear process. Therefore, iterative/incremental methods are adopted. In these methods, it is assumed that the structural behaviour is known at time $t$ and the objective of the structural analysis is to find the structural behaviour at time $t+\Delta t$ after an interval $\Delta t$. Various parameters describing the structural behaviour are linearized during this interval. Depending on whether these structural variables are measured with respect to the initial structural configuration $(t=0)$ or the immediately previous known state $(t)$, either total Lagrangian or updated Lagrangian formulations may be adopted. In this analysis, the total Lagrangian formulation is followed. Starting from the principle of virtual work, the response of the structure to externally applied loads can be determined from the following expression [5].

$\int_{v} \operatorname{Ce} \delta \mathrm{edV}+\int_{\mathrm{v}} \mathrm{S} \delta \eta \mathrm{dV}=\delta^{\mathrm{t}+\Delta t} \mathrm{~W}_{\mathrm{ext}}-\int_{\mathrm{v}} \mathrm{t} S \delta \mathrm{edV}$

where $\mathrm{C}$ is the stress-strain tensor of the structural material; e and $\eta$ are respectively the linear and non-linear part of the strain tensor. ' $S$ is the known stress tensor at time $t ;{ }^{i+\Delta t} W_{\text {ext }}$ is the work done by external forces and $\delta$ represents variation in the appropriate parameter. Adopting the total Lagrangian formulation, the integration is performed over the undeformed configuration.

Applying the finite element method, the structure is divided into a number of elements connected by nodes. The displacement field of the structure is represented by displacements at these nodes using shape functions. Expressing the strain as a function of nodal displacements, the structural behaviour can then be expressed as the relationship between loads and deflections at these nodes as:

$\left(\left[\mathrm{K}_{\mathrm{L}}\right]+\left[\mathrm{K}_{\mathrm{NL}}\right]\right)\{\mathrm{u}\}=\left\{{ }^{1+\Delta t} \mathrm{R}\right\}-\{\mathrm{F}\}$

in which, $\left[{ }^{t} \mathrm{~K}_{\mathrm{L}}\right],\left[\mathrm{K}_{\mathrm{N}}\right]$ are the flexural and geometrical parts of the structural tangent stiffness matrices due to linear and non-linear parts of strains; $\{u\}$ is the nodal displacement vector; $\left\{{ }^{1+\Delta} \mathrm{R}\right\}$ and $\{\mathrm{F}\}$ are respectively vectors of the applied loads and resistant forces at nodes.

\section{Application to Shell Structures}

Finite element analysis of shell structures has been the subject of many research studies due to the inherent complexity of this type of structure. Basically, three distinct approaches have been developed [6] and these are:

1. The shell element is formed by the superimposition of a plate bending element and a membrane element;

2. A particular shell theory is followed and discretised;

3. General three dimensional continuum mechanics equations are discretised and degenerated to general shell behaviour using isoparametric displacement interpolation functions

In this study, the third approach is adopted due to its generality and versatility when applied to general shell structures. In this method, the same shape functions are used to represent the element geometry and the displacement field. Referring to figure 1 which shows a typical shell element, the position of a generic point at time t may be expressed as: 


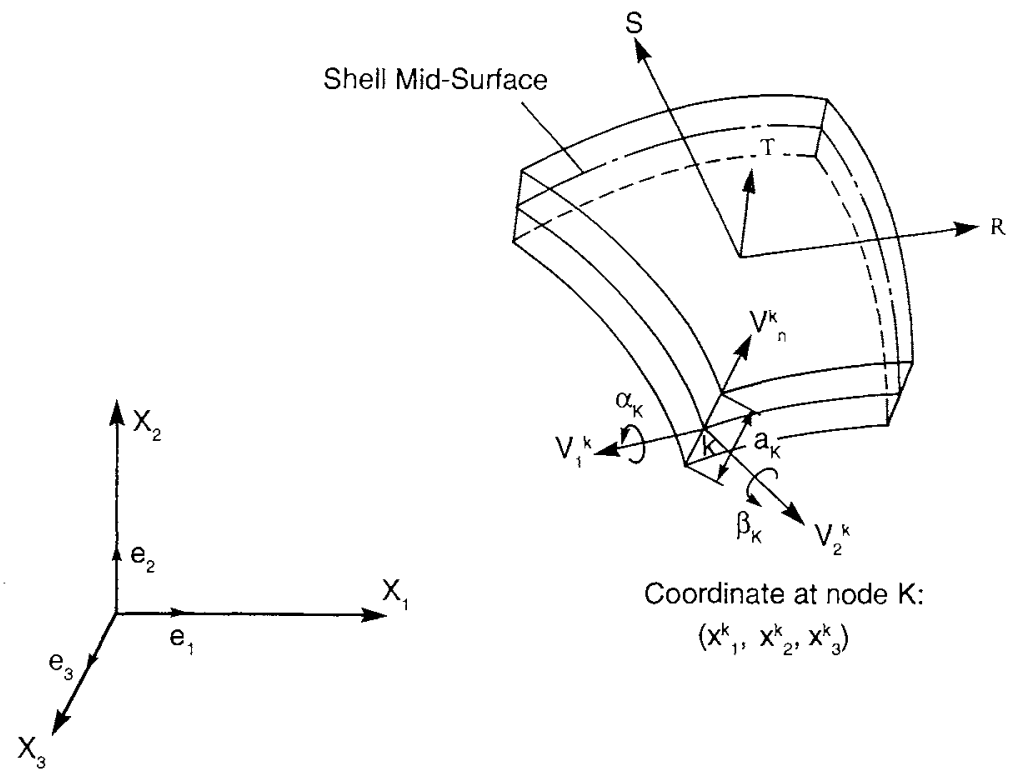

Figure 1. A typical quadrilateral shell element

$\mathrm{X}_{\mathrm{i}}=\sum \mathrm{h}_{\mathrm{k}}\left(\mathrm{X}_{\mathrm{i}}^{\mathrm{k}}+\mathrm{T} / 2 \mathrm{a}_{\mathrm{k}}{ }^{\prime} \mathrm{V}_{\mathrm{ni}}{ }^{\mathrm{h}}\right) \quad(\mathrm{k}=1$ to $\mathrm{N})$

where

R-S-T

${ }^{t} X_{i}^{k}$

$a_{k}$

${ }^{t} V_{n i}^{k}$

$\mathrm{h}_{\mathrm{k}}$

natural coordinate system (values equal to -1 or 1 at boundaries)

Cartesisan coordinates of the kth node

shell thickness of the kth node

normal unit vector components at node $k$

$\mathrm{N}$

isoparametric interpolation function at node $\mathrm{k}$

number of nodes of the element

This equation is then used to evaluate the displacement field of the element as the increment in coordinates relative to its initial configuration. Obviously, shell elements can have a variable number of nodes. Some typical shell elements are shown in figure 2. Methods of generating shape functions $h_{k}$ for various types of shell elements are given by Zienkiewicz [7].

In the analysis of degenerated shell elements, it is assumed that stress corresponding to the direction $\mathrm{T}$ which is perpendicular to the shell mid-surface $\mathrm{R}-\mathrm{S}$ is zero. 

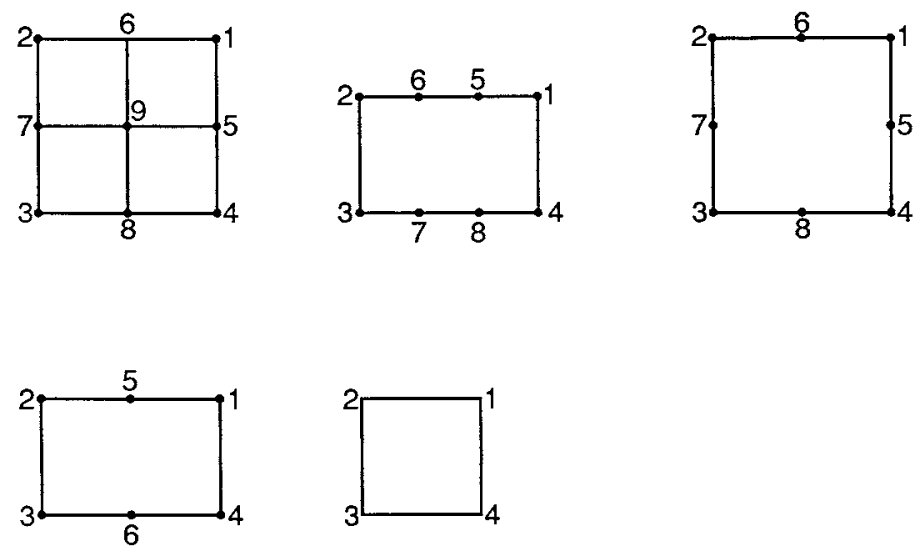

Figure 2. Types of shell element

\section{Layered Integration Approach}

Equation (1) shows that a 3-D integration over the whole volume of the shell element is required in order to form its stiffness matrix and stress resultant vector of equation (2). This can be done using the Gauss integration scheme [7]. However, if the shell element possesses discontinuity of material properties along its thickness as in laminated composite structures or reinforced concrete structures, an appropriate scheme of through thickness integration has to be carried out to take into consideration this material variation within thickness. An efficient way is to employ the layered approach [8]. In this method, the thickness of the shell is divided into a number of layers whose properties are represented by those at its mid-surface and assumed to be constant throughout the thickness direction so that the 3-D integration may be separated into the integration along the thickness and then across the mid-surface.

$$
F=\int_{-1}^{1} \int_{-1}^{1} \int_{-1}^{1} f(R, S, T)\left|J_{k}\right| d T d S d R=\int_{-1}^{1} \int_{-1}^{1} \sum_{k=1}^{L}\left(\int_{T_{k}}^{T_{k}} f\left(R, S, T_{k}\right)\left|J_{k}\right| d R d S\right.
$$

Assuming the function to be integrated is $f(R, S, T)$ and its integrated value is $F$ :

where $L$ is the total number of layers. $T_{k 1}$ and $T_{k 2}$ are lower and upper bounds of the natural coordinates of the $k$ th layer in the thickness direction and $\left|\mathrm{J}_{\mathrm{k}}\right|$ is the determinant of the Jacobian transformation matrix of the local coordinate system $\left(\mathrm{X}_{1}-\mathrm{X}_{2}-\mathrm{X}_{3}\right)$ with respect to the natural coordinate system R-S-T.

Since $f\left(R, S, T_{k}\right)$ and $\left|J_{k}\right|$ are assumed to be constant within each layer, the above equation is simplified to

$$
F=\int_{-1}^{1} \int_{-1}^{1}\left[\sum_{k-1}^{L} f\left(R, S, T_{k}\right)\left|J_{k}\right|\left(T_{k 2} T_{k 1}\right)\right] d R d S
$$

The surface integration is carried out using the 2-D Gauss integration scheme [7]. 


\section{Modification of the 4-node Element}

One difficulty which may be encountered when using the method described above is that for thin shells, the computed shell behaviour may exhibit shear locking [7] if full integration is employed to evaluate various matrices. That is to say, the shell structure has an artificially very high shear stiffness. To overcome this problem, the scheme of reduced and/or selective integration has been proposed [7].

While this method has been found to be successful for many problems, other difficulties appear. One is that when using this method for lightly restrained shell structures, spurious zero energy modes may occur and as a result of which unstable, worst of all, stable but completely fictitious solutions may appear. Moreover, much experience is needed to employ this scheme.

Considering that nonlinear behaviour is always encountered in the analysis, high order integration is always necessary to trace the variation of various parameters. Therefore, the reduced/selective integration method should be avoided if possible. High order elements may be used, however, this is often achieved at the expense of high computational cost. Alternative methods for lower order elements are required.

Since the problem lies with the evaluation of shear strains, one obvious alternative is to find the optimal shear strain sampling points and then interpolate shear strains for the element. This method has been adopted by Dvorkin and Bathe [9] for 4-node element and also by Huang [8] for 9-node quadratic Lagrange element. In this analysis, the modification of the 4-node element by Dvorkin and Bathe [9] is adopted.

The optimal shear strain sampling points for the 4-noded shell element are found to be at the 4 interception points of the natural coordinate axes R-S with the edges of the shell element in its mid-surface. The shear strains at these points are directly evaluated using displacements obtained from equation (3). Linear distribution of these shear strains are assumed in the shell element mid-surface and they are constant in the thickness direction.

\section{Temperature Effects}

The theory outlined above is generally applicable to any material. The behaviour of structures is different at elevated temperature from that at cold condition due to temperature dependent material properties, namely temperature dependent stress-strain relationships and thermal strains. In the present analysis, the total strain for concrete includes thermal expansion, instantaneous stress related strain, creep strain and transient thermal strain [10]. For steel material, the total strain consists of instantaneous stress related strain, thermal expansion and creep strain. Thermal strains can be simply treated as initial strains. However, the derivation of the temperature dependent elastic-plastic stress-strain relationship is more involved. Ueda and Yamakawa [11] obtained the following relationship:

$$
\{S\}=\left[{ }^{\mathrm{T}} \mathrm{C}_{\mathrm{ep}}\right]\left\{\mathrm{e}-\mathrm{e}_{\mathrm{e}}{ }^{\mathrm{T}}-\mathrm{e}_{\mathrm{th}}\right\}+\left(\left[{ }^{\mathrm{T}} \mathrm{C}_{\mathrm{e}}\right]\{\partial \mathrm{f} / \partial \mathrm{S}\} \partial \sigma_{\sqrt{ }} / \partial \mathrm{T}\right) / \mathrm{G}
$$

where $S$ represents stress; $\left[{ }^{\mathrm{T}} \mathrm{C}_{\mathrm{e}}\right]$ is the material elastic stress-strain relationship at elevated temperature $\mathrm{T} ;\left[{ }^{\mathrm{T}} \mathrm{C}_{\mathrm{ep}}\right]$ is the material elastic-plastic constitutive matrix at elevated temperature $\mathrm{T}$, which can be derived in a similar way to cold condition analysis [7]; $\mathrm{e}$ is the increment in the 
current total strain; $e_{\mathrm{e}}{ }^{\mathrm{T}}$ is temperature induced elastic strain increment under constant stress due to variation of $\left[{ }^{T} C_{e}\right]$ with temperature; $e_{t h}$ is the thermal strain increment; f and $\sigma_{y}$ are respectively the multiaxial and uniaxial yield stress functions at temperature $\mathrm{T}$; and $\mathrm{G}$ is:

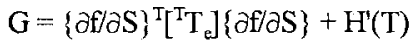

in which $\mathrm{H}^{\prime}(\mathrm{T})$ is the tangent to the material uniaxial stress-plastic strain curve at temperature $\mathrm{T}$.

\section{Stress-strain Relationship of Steel and Concrete Materials}

For steel, three models of temperature dependent stress-strain relationships are included in the present analysis. They are the British Steel tabulated data [12], the Ramberg-Osgood curve-fitting description of the British Steel test data [13] and the mathematical model proposed in the European steel fire resistant design code [14]. The layered integration approach is utilised to accommodate the steel reinforcement. It is modelled as a smeared layer with uniaxial material properties.

For concrete at room temperature, the model used by Figueiras [15] is adopted. This model describes the concrete material stress-strain relationship in compression as parabolic until its ultimate compressive stress and followed by a constant stress plateau until crushing. The tensile stress-strain relationship is linear until the maximum tensile strength is reached and followed by a linear reduction in tensile stress with increasing tensile strain until cracking occurs. The behaviour of concrete at elevated temperature is similar to the room temperature behaviour but with reduced compressive and tensile strength as well as reduced Young's modulus.

\section{NUMERICAL EXAMPLES}

A computer program has been developed according to the theory described above. The following results are presented to illustrate its capacity and accuracy.

\section{Analysis of Reinforced Concrete Square Plates at Room Temperature}

Figueiras [15] reported test results and computer analytical predictions of 3 simply supported square reinforced concrete plates loaded by a concentrated force at the centre, tested by Duddeck et al [16]. These 3 plates were studied using the present analysis. Material and geometrical data are presented in figure 3 . Because of symmetry, only a quarter of each plate was modelled. Six by six 4-noded shell elements with modified shear stress distribution were used to discretise the plate.

Figures 4 show the comparison for load-deflection curves for each plate. All figures show good correlation between test and predicted results in terms of both deflection and ultimate load.

\section{Reinforced Concrete Slabs in Fire}

Due to the lack of experimental data, the program is checked against two pairs of simply 

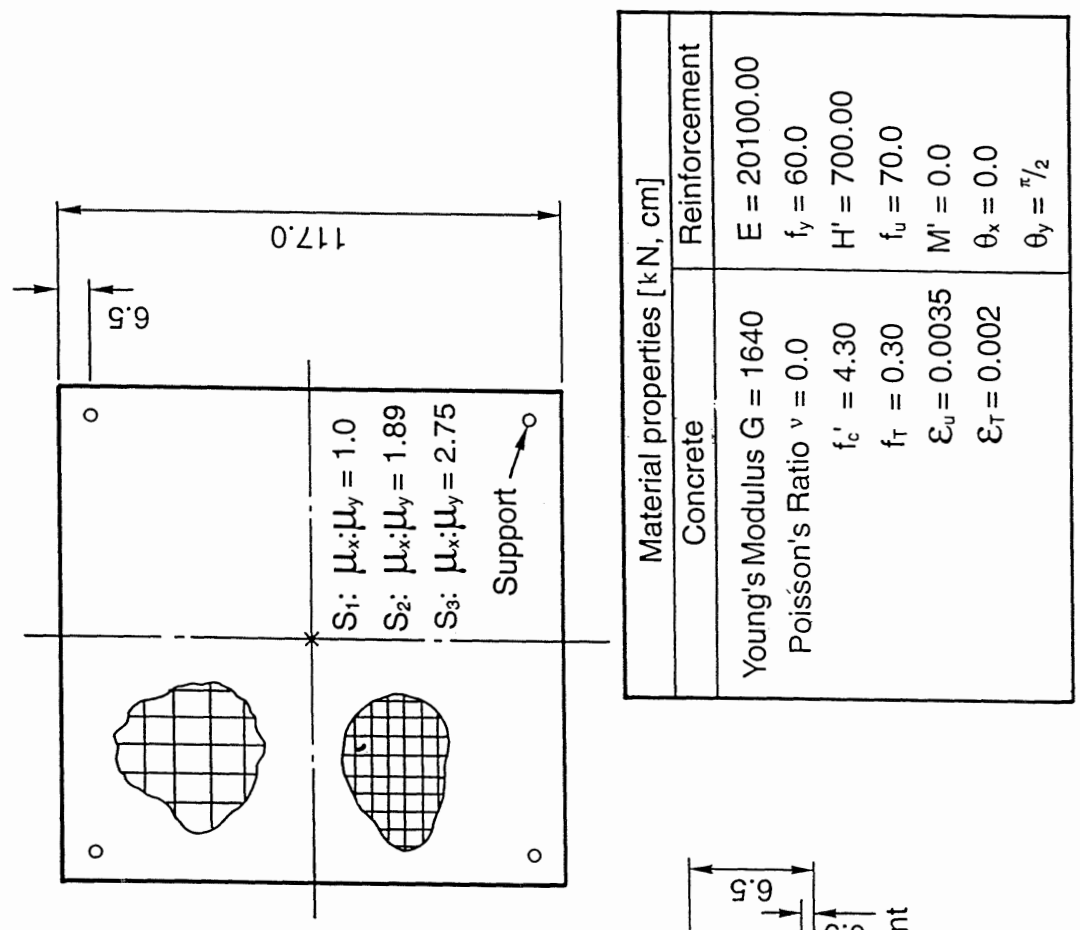

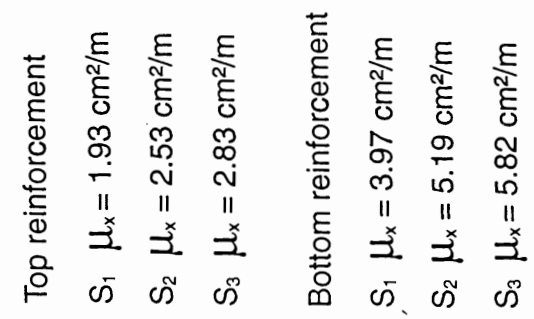

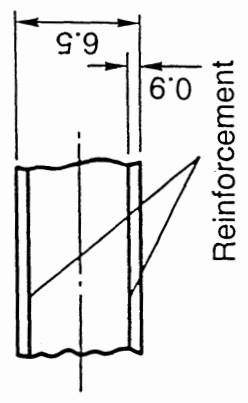

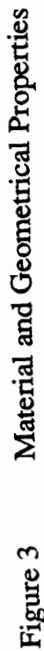




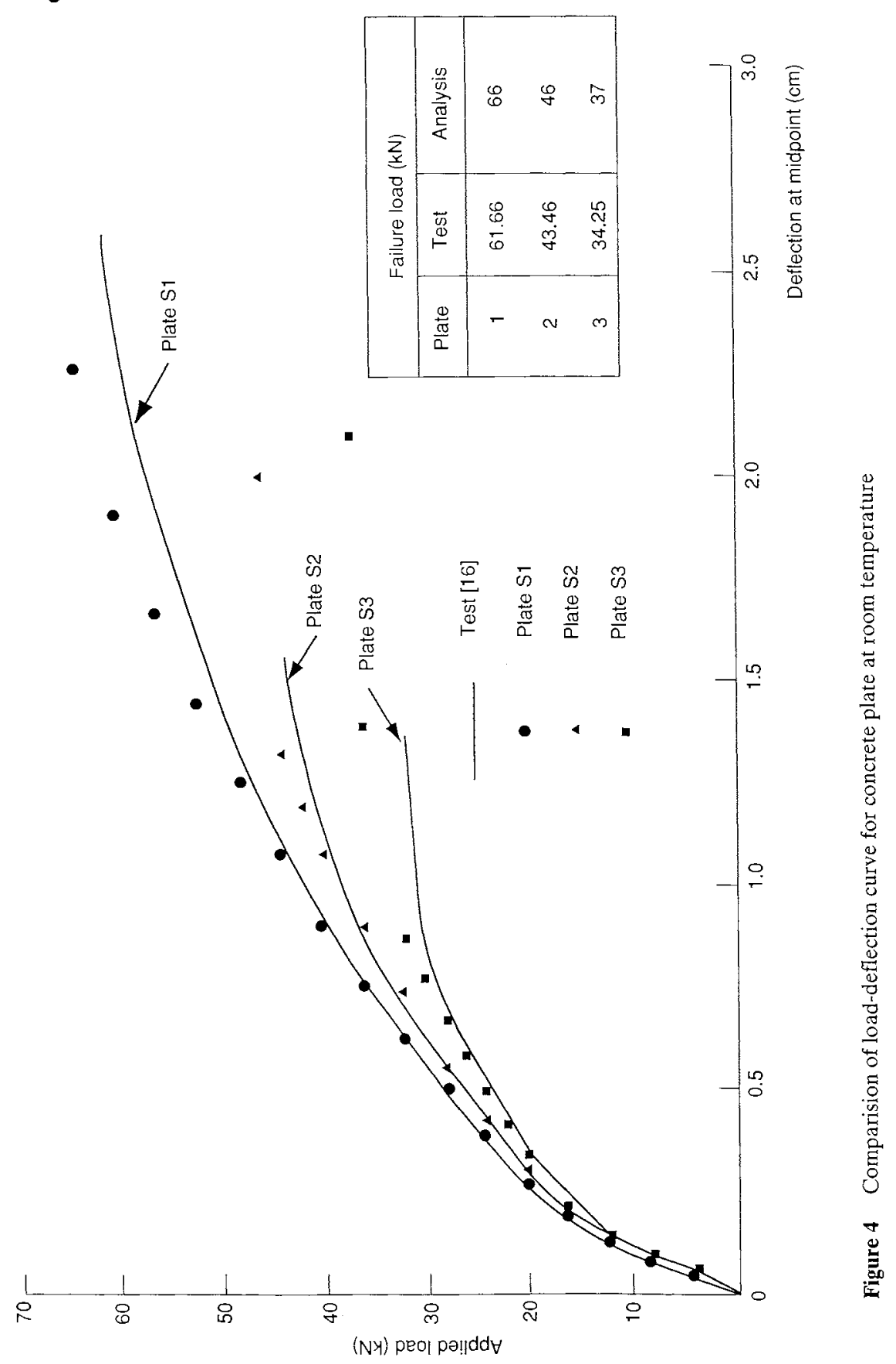


supported beam-type reinforced concrete slabs under different fire conditions [17]. These tests were conducted specifically at Warrington Fire Research Centre under contract to the Fire Research Station, UK. All slabs had the same geometrical and material properties. They were $4500 \mathrm{~mm}$ long, $930 \mathrm{~mm}$ wide and $150 \mathrm{~mm}$ thick. The concrete had a compressive strength of $\$ 2$ $\mathrm{N} / \mathrm{mm}^{2}$ and density of $2388 \mathrm{~kg} / \mathrm{m}^{3}$. 10 high strength steel bars of $8 \mathrm{~mm}$ diameter with a yield stress of $482 \mathrm{~N} / \mathrm{mm}^{2}$ at $90 \mathrm{~mm}$ centre and $25 \mathrm{~mm}$ concrete cover were used as reinforcement. The first pair were subject to the BS 476 Part 8[18] standard furnace fire whilst the second was subject to the hydrocarbon fire. Each pair consisted of one loaded $\left(1.5 \mathrm{kN} / \mathrm{m}^{2}\right)$ and one unloaded slab. These tests were simulated by the present analysis using eight 4-noded shell elements with shear strain modification. Measured temperature values were used in the analysis.

Figures $5 \& 6$ and $7 \& 8$ compare results from the present analysis with test results for lateral deflection and axial deformation versus fire test time relationships. They show that the predicted results follow the test results reasonably closely in each comparison, especially the trend of all slabs to axially extend (mainly the effect of thermal expansion) followed by contraction (due to the effect of large lateral deflection) is predicted accurately using the present computer program

\section{CONCLUSIONS AND FURTHER WORK}

The theoretical background of a finite element program for the analysis of general shell structures representing floors and walls of a building under fire attack is described. The features of the computer program include degenerated isoparametric shell elements with variable nodes; a 4-noded shell element with enhanced shear strain distribution; geometrical nonlinearity and material nonlinearity at both room and elevated temperature. Reasonably good agreement with test results of reinforced concrete plates at both room temperature and elevated temperature show the capacity and accuracy of the computer program. To enable the program to be used confidently, more experimental results are required for verification.

\section{REFERENCES}

1. Jeanes,D.C., Application of the Computer in Modelling Fire Endurance of Structural Steel Floor Systems, Fire Safety Journal, 9 , pp. 119-135, 1985

2. Nizzamuddin,Z. and Bresler,B.: Fire Response of Concrete Slabs, ASCE Proceedings, Journal of Structural Division, 105 (ST8), pp. 1653-1671August 1979

3. O'Meagher,A.J. and Bennetts,I.D., Modelling of Concrete Walls in Fire, Fire Safety Journal, 17, pp. 315-335, 1991

4. Wang, Y.C. and Moore,D.B., Fire Resistance of Steel Frames, in Structural Design for Hazardous Loads, ed. Clarke,J.L., Garas,F.K. and Armer,G.S.T., E\&FN Spon, pp.439-448, 1992

5. Bathe,K.J., Finite Element Procedures in Engineering Analysis, Prentice-Hall, Inc., Eaglewood Cliffs, New Jersey, 1982

6. Figueiras,J.A and Owen,D.R.J., Analysis of Elasto-plastic and Geometrically Anisotropic Plates and Shell in Finite Element Program Software for Plates and Shells ed. Hinton,E 
and Owen,D.R.J., University Collage of Swansea, 1984

7. Zienkiewicz,O.C., The Finite Element Method. McGraw-Hill Book Company (UK) Limited, 1977

8. Huang,H.C., Defect-free Shell Elements, Ph.D thesis, Department of Civil Engineering, University College of Swansea, 1986

9. Dvorkin,E.N. and Bathe,K.J., A Continum Mechanics Based Four-node Shell Element for General Nonlinear Analysis, Engineering Computing. 1, pp. 77-88, 1984

10. Anderberg,Y., Fire-exposed Hyperstatic Concrete Structures - An Experimental and Theoretical study, Lund Institute of Technology, Lund, Sweden, 1976

11. Ueda,Y. and Yamakawa, T., Thermal Nonlinear Behaviour of Structures, in Advances in Computational Methods in Structural Mechanics and Design, ed. Oden,J.T., Clough, R.W. and Yamamoto, Y., 2nd U.S.-Japan Seminar on Matrix Methods of Structural Analysis and Design, pp. 375-392, August 1972

12. Kirby,B.R., Recent Development and Application in Structural Fire Engineering Design - A Review, Fire Safety Journal, 11, pp. 141-179, 1986

13. Saab,H.A. and Nethercot,D.A., Modelling Steel Frame Behaviour under Fire Conditions, Engineering Structures, 13, pp. 371-382, 1991

14. Commission of the European Communities, Eurocode No. 3. Design of Steel Structures, Part 1.4: Fire Resistance, Draft prENV 1993-1-2, British Standards Institution, 1992

15. Figueiras,J.A., Ultimate Load Analysis of Anisotropic and Reinforced Concrete Plates and Shells, Ph.D Thesis. Department of Civil Engineering, University of Swansea, 1983

16. Duddeck,H., Criebenow,G. and Shaper,G., Material and Time Dependent Nonlinear Behaviour of Cracked Reinforced Concrete Slabs, in Nonlinear Behaviour of Reinforced Concrete Spatial Structures, Vol. 1. Preliminary Reports IASS Symposium held in Darmstadt, eds. Mehlhorn,G., Ruhle,H. and Zerna,W., Werner-Verlay Dusseldorf, pp. 101-113, July 1978

17. Cooke,G.M.E., Private Communication, 1991

18. British Standard Institution, British Standard: Fire Tests on Building Materials and Structures. Part 21: Methods for Determination of the Fire Resistance of Loadbearing Elements of Construction. British Standards Institution, 1987 


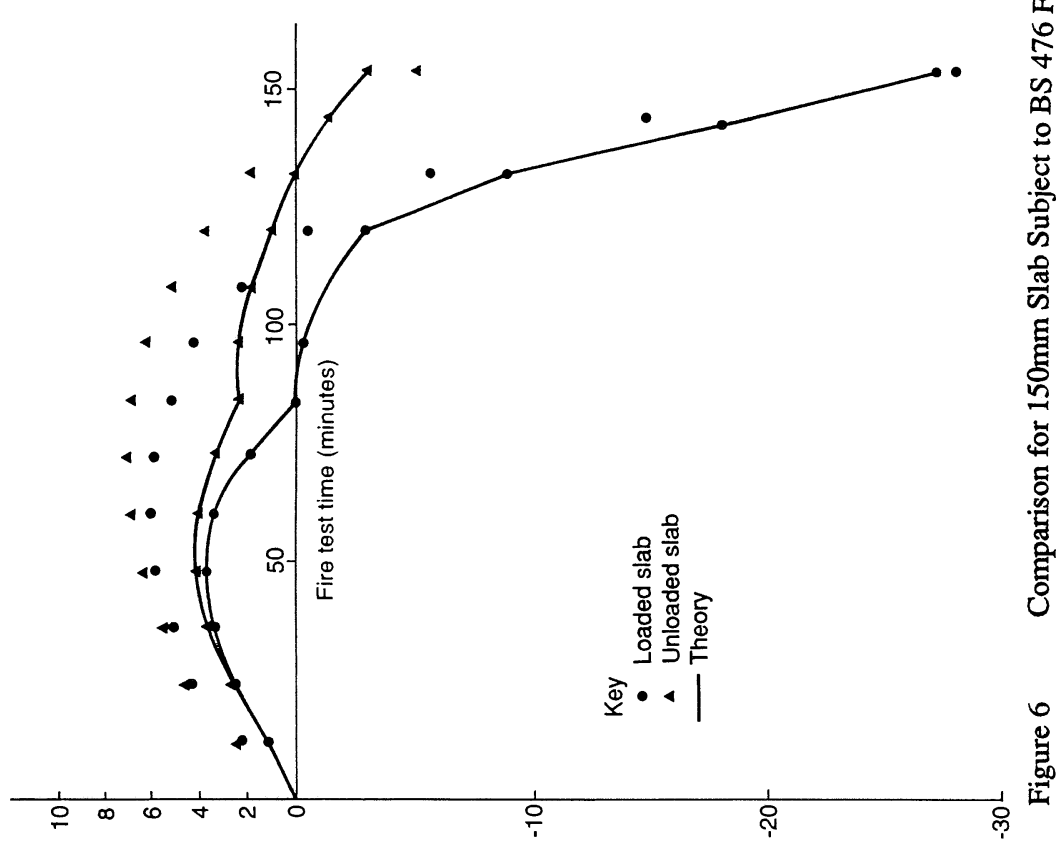

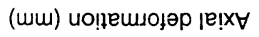

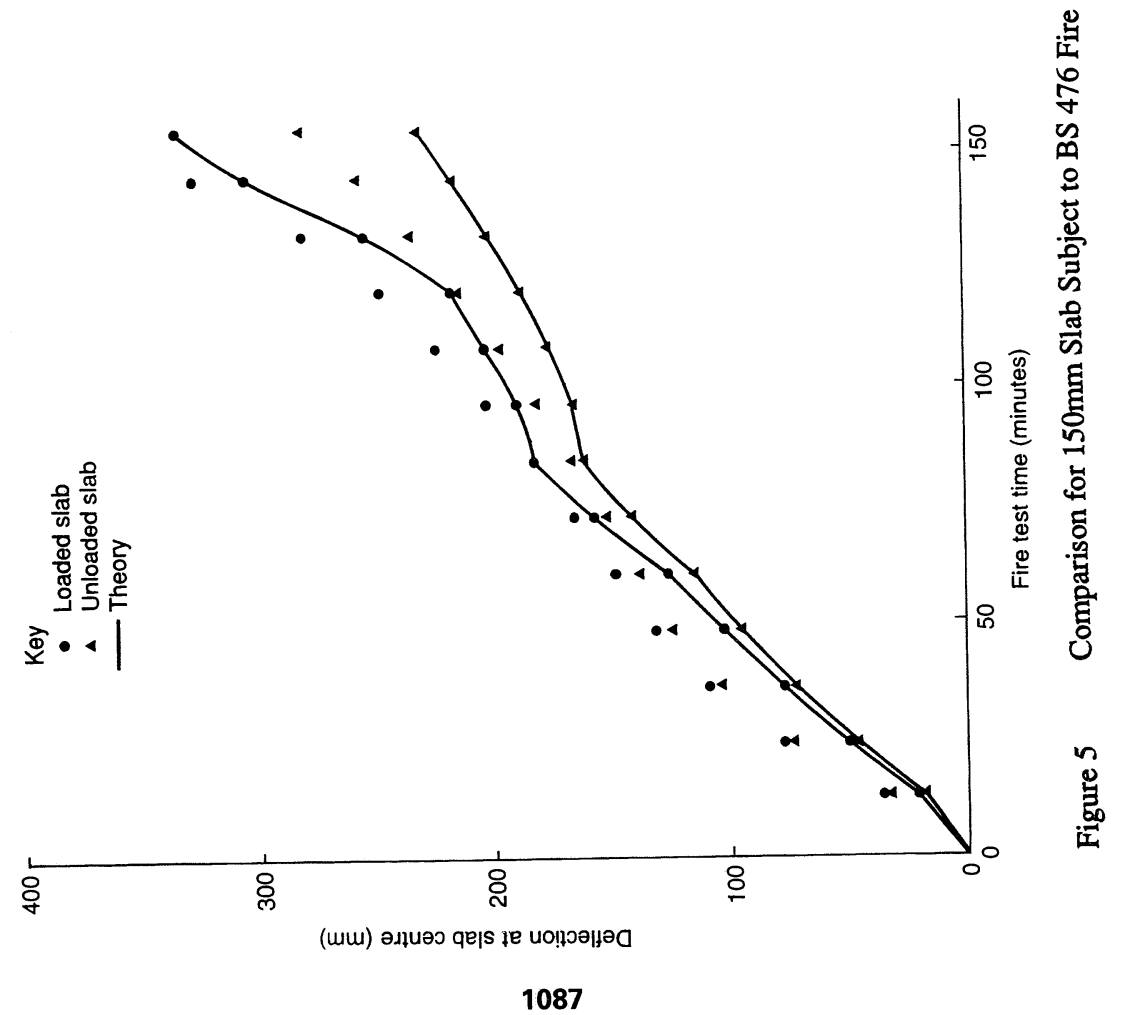



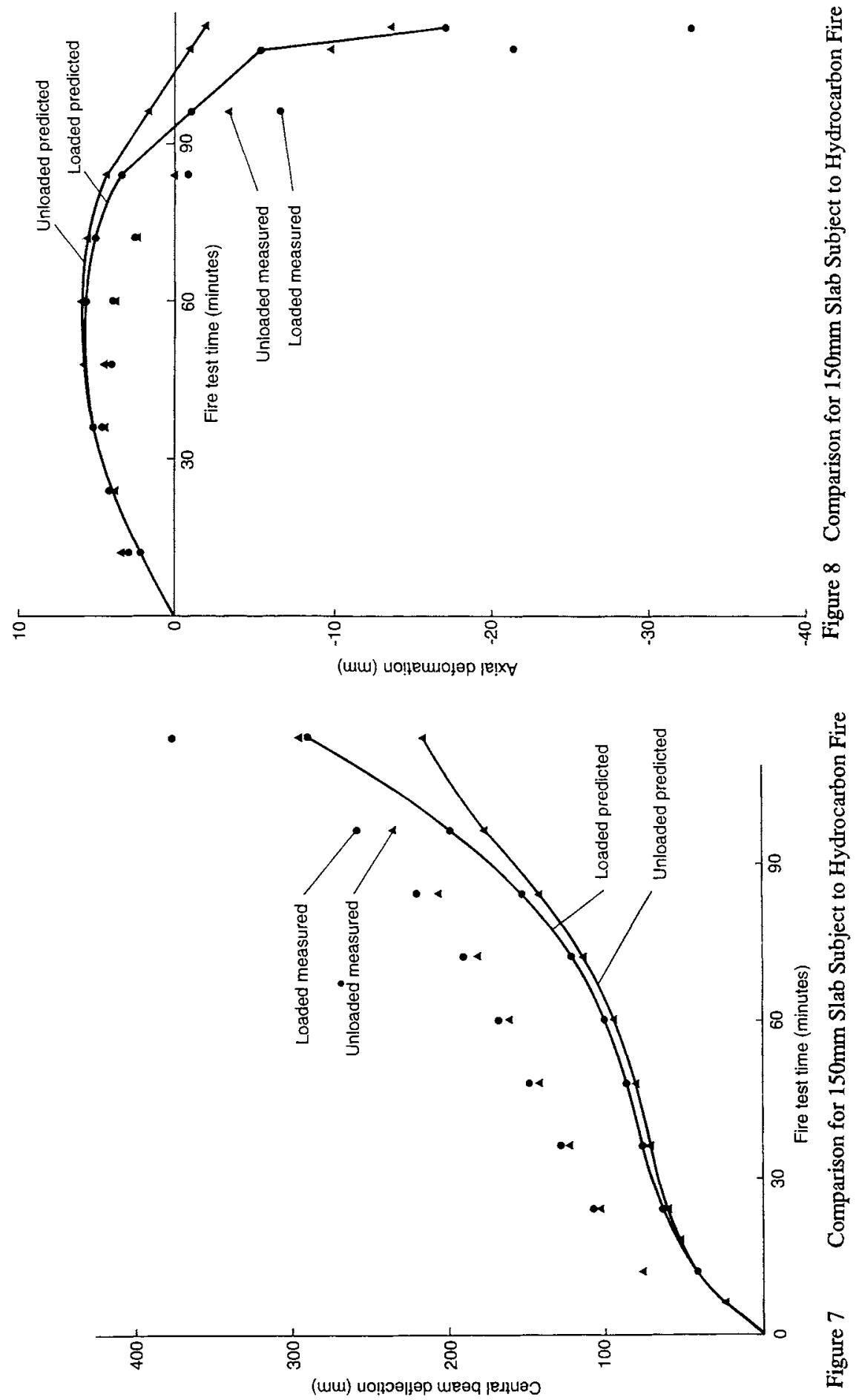